\title{
SUPPORT EDUKASI DENGAN DIGITAL STORYTELLING TERHADAP PENINGKATAN SELF CARE OSTOMATE DI MAKASSAR TAHUN 2019
}

\section{SUPPORT EDUCATION WITH DIGITAL STRORYTELLING OF SELF CARE OSTOMATE IMPROVEMENTS IN MAKASSAR IN 2019}

\author{
Yuliana Syam, Elly Lilianti Sjattar, Abd. Majid, Ariyanti Saleh \\ Program Studi Keperawatan,Fakultas Keperawatan, Universitas Hasanuddin
}

Alamat Korespondensi: Fakultas Keperawatan, Universitas Hasanuddin, Makassar, 90245

HP: +6281342012733

\begin{abstract}
Abstrak
Colostomy adalah tindakan pembedahan pembuatan lubang sementara atau permanen dari usus besar melalui dinding perut yang biasanya dilakukan sebagai terapi pada penderita kanker usus atau anus. Angka kejadian terus meningkat tiap tahunnya, dan pembuatan stoma akan menimbulkan permasalahan bagi penderita baik fisik, mental, emosional terkait aksesoris colostomy, dan bagaimana melanjutkan kembali kehidupan secara normal. Ketakutan yang dihadapi akan mencakup perasaan perubahan citra tubuh, peran dan fungsi dalam pemenuhan aktivitas sehari-hari dan berdampak terhadap penurunan daya tahan tubuh. Salah satu cara untuk meningkatkan pengetahuan dan penerimaan penderita colostomy adalah dengan meningkatkan self eficasy dan self care dari klien dengan stoma yang dilakukan melakukan terapi bercerita/storytelling. Metode Peneelitian ini adalah Intervensi storytelling dilakukan selama 12 menit yang sudah disesuaikan secara kultural dan linguistik yang terdiri dari pengantar, cerita, dan pesan pendidikan managemen perawatan serta penutup.Wawancara terstruktur digunakan untuk menilai intervensi untuk penerimaan, tingkat minat, dan kegunaan.mSetelah menonton videonya, peserta menilai kepercayaan diri dan motivasinya serta kemampuan dalam pengelolaan manajemen perawatannya sebagai ostomate. Pengukuran self care dengan menggunakan kuisioner Stoma-Care SelfEfficacy Scale (SCSES) Hasil penelitian mengemukakan bahwa terjadi peningkatan pengetahuan dan self care penderita stoma setelah dilakukan support edukasi dengan story telling. Sebagian besar $(62,5$ $\%)$ penderita mengalami self efficacy tinggi, adanya respon yang positif dalam hal pemenuhan kebutuhan aktifitas sehari-hari termasuk dalam hal beribadah, dan tetap semangat dalam menjalani aktiftas sehari-hari dengan menggunakan stoma. Kesimpulan dari penelitian ini adalah Story telling mampu memberikan semangat dan menularkan respon positif ke ostomate lainnya, sehingga akan meningkatkan status kesehatan ostomate.
\end{abstract}

Kata kunci: Colostomy, Storytelling, ostomate, Self Care, Stoma

\begin{abstract}
Colostomy is the surgical procedure of making a temporary or permanent hole from the large intestine through the abdominal wall which is usually done as a therapy for patients with colon or anal cancer. The incidence continues to increase each year, and stoma making will cause problems for sufferers both physically, mentally, emotionally related to colostomy accessories, and how to resume normal life. Fear faced will include feelings of changes in body image, roles and functions in fulfilling daily activities and impact on decreased endurance. One way to increase the knowledge and acceptance of colostomy sufferers is to improve self-efficacy and self care from clients with a stoma conducted storytelling therapy. This research method is a 12-minute storytelling intervention conducted culturally and linguistically adapted consisting of introduction, stories, and messages of care management education and concluding. Structured interviews are used to assess interventions for acceptance, level of interest, and usefulness. After watching the video, participants assess their confidence and motivation and ability in managing their care management as an ostomate. Measurement of self care by using the Stoma-Care Self-Efficacy Scale (SCSES) questionnaire The results of the study revealed that an increase in knowledge and self care of patients with stoma after educational support was done with story telling. Most (62.5\%) sufferers experience high self-efficacy, a positive response in terms of meeting the needs of daily activities including in terms of worship, and keep the spirit in undergoing daily activities using a stoma. The conclusion of this research is Story telling is able to encourage and transmit positive responses to other ostomates, so that it will improve the health status of ostomates.
\end{abstract}

Keywords: Colostomy, Storytelling, ostomate, Self Care, Stoma 


\section{PENDAHULUAN}

Colostomy adalah tindakan pembedahan pembuatan lubang sementara atau permanen dari usus besar melalui dinding perut yang biasanya dilakukan sebagai terapi pada penderita kanker usus atau anus.(Black et al 2009). Angka kejadian terus meningkat tiap tahunnya, dan pembuatan stoma akan menimbulkan permasalahan bagi penderita baik fisik, mental, emosional terkait aksesoris colostomy, dan bagaimana melanjutkan kembali kehidupan secara normal.(YKI, 2014; Kirkland-Kyhn, Martin, Zaratkiewicz, Whitmore, \& Young (2018),).

Ketakutan yang dihadapi akan mencakup perasaan perubahan citra tubuh, peran dan fungsi dalam pemenuhan aktivitas sehari-hari dan berdampak terhadap penurunan daya tahan tubuh. Oleh karena itu, salah satu upaya yang dapat dilakukan untuk meningkatkan rasa percaya diri terhadap berubahan akibat adanya stoma dan menghindari kejadian komplikasi pada perawatan stoma dapat dilakukan edukasi dan dukungan termasuk untuk meningkatkan kemampuan keterampilan cara merawat stoma mulai sejak dini dan dimulai sebelum operasi dan dilanjutkan pada pasca operasi selama pasien masih dirawat dirumah sakit sehingga saat pulang kerumah mereka sudah dapat merawat stoma mereka sendiri (Jennie Burch 2011; Cheng et al. 2013; Grant, Marciaook, Wendel, and Krouse 2013).

Salah satu metode edukasi dengan video storytelling/bercerita diharapkan mampu mengatasi permasalah diatas. Bercerita merupakan satu media komunikasi terapeutik untuk mengungkapkan perasaan seseorang saat mengalami suka duka dalam menjalani suatu perawatan yang digunakan sebagai motivasi kepada orang lain untuk tetap semangat (Wieland et al., 2017). Storytelling juga dapat dibuat dalam bentuk digital, cerita digital dibuat dengan paduan gambar, musik, narasi dan suara bersama, sehingga memberikan efek yang mendalam dan efek yang lebih menarik terkait karakter, situasi, pengalaman, dan wawasan (Snyder \& Lindquist, 2010).

Penelitian yang dilakukan oleh Summers, (2018), menunjukkan bahwa support yang diberikan oleh ostomate kepada ostomate yang lain dapat meningkatkan adaptasi psikososial pada pasien stoma. Pasien dengan stoma baru akan lebih termotivasi untuk survive dengan kondisinya setelah mendengar cerita atau pengalaman dari orang lain yang sama dengannya. sehingga tujuan dilakukan kegiatan pengabdian masyarakat ini adalah meningkatkan penerimaan pasien tentang kondisi penyakitnya dan meningkatkan kemampuan pasien untuk merawat dirinya sebagai pengguna stoma, melalui media yg digunakan dengan digital storytelling, dalam hal ini storytellernya dibawakan oleh seorang pengguna Stoma.

\section{METODE}

\section{Lokasi kegiatan Pengabdian masyarkat:}

Metode pemecahan masalah dalam pengabdian masyarakat ini yaitu menggunakan metode edukasi dengan menggunakan video storytelling. Lokasi kegiatan pengabdian masyarakat ini dilakukan di ruang Bedah Digestif Lontara 1 atas depan RSU. Dr. Wahidin Sudirohusodo pada tanggal 20 Juli 2019, dalam kegiatan ini dihadiri oleh ketua beserta anggota Tim melakukan intervensi ke pasien stoma didampingi oleh kepala ruangan lontara 2 atas depan dalam memberikan edukasi ke pasien dengan menggunakan media video story telling. Kegiatan ini melibatkan pasien-pasien yang telah terpasang stoma di ruang lontara 2 atas depan RSUP Dr. Wahidin Sudirohusodo Makassar. Kegiatan ini terdiri atas pembuatan video storytelling, pembuatan bookled bahan edukasi, dan dilanjutkan memberikan support edukasi dengan menggunakan media video storytelling bersama-sama dengan perawat ruangan. 
Pada sesi pemberian support edukasi dimulai dengan perkenalan sekaligus menyampaikan tujuan dan proses kegiatan serta isi dari video digital storytelling tersebut, menilai kemampuan perawatan stoma saat ini, lalu dilanjutkan dengan pemutaran video digital story telling diselingi dengan penjelasan setelah pemutaran video telah dilakukan. Memberikan demostrasi tentang cara perawatan stoma, dan teralhir melakukan evaluasi terhadap isi konten dari edukasi yang telah dilakukan.

\section{Desain dan Variabel}

Desain penelitian observasional study dengan Variabel penelitian terdiri atas Variabel Independen Support edukasi dengan Storytelling dan Variabel dependent Self Care.

\section{Populasi dan Sampel}

Populasi dalam kegiatan pengabdian masyarakat ini adalah semua pasien stoma yang dirawat di RS. Dr. Wahidin Sudirohusodo.

Sampel dalam penelitian ini adalah Pasien yang dirawat di Ruang Lontara 2 Atas
Depan Bedah Digestif, Pasien yang telah menjalani jenis tindakan operasi berupa kolostomi maupun ileostomi hari < 6 bln, Pasien yang bersedia untuk memberikan persetujuan tertulis., Mampu berkomunikasi dalam bahasa Indonesia dan bahasa daerah (bugis/makassar) dan petugas perawat yang bertugas di ruangan tersebut.

\section{Pengumpulan data.}

Pengumpulan data dilakukan oleh tim dengan menggunakan kuesioner. Data yang di input terdiri atas Data demografi (umur, pendidikan, jenis kelamin, pekerjaan, status pernikahan) dan data self care dengan menggunakan kuisioner Stoma-Care SelfEfficacy Scale

\section{Analisis data}

Data yang diolah terdiri atas data demografi pasien stoma dan data self care yang ditampilkan dalam bentuk data distribusi frekwensi yang diolah dengan menggunakan SPSS for windows 11.5.

Tabel 1:Karakteristik Pasien Berdasarkan Umur, Jenis Kelamin, Pendidikan Status Pernikahan, dan Pekerjaan Pasien di Ruang Rawat Inap Lontara 2 Atas Depan RSUP Dr. Wahidin Sudirohusodo

\begin{tabular}{lcc}
\hline \multicolumn{1}{c}{ Variabel } & Jumlah(n) & Persentase (\%) \\
\hline Umur & Mean \pm SD $55(8.85)$ & \\
Jenis Kelamin : & 5 & 62,5 \\
$\quad$ Laki-laki & 3 & 37,5 \\
Perempuan & & \\
Pendidikan : & 5 & 62,5 \\
$\quad$ SD & 1 & 12,5 \\
SLTP & 1 & 12,5 \\
SLTA & 1 & 12,5 \\
Diploma/Sarjana & & \\
Status Pernikahan : & 7 & 87,5 \\
$\quad$ Menikah & 1 & 12,5 \\
Duda/janda & & \\
Pekerjaan : & 4 & 50 \\
$\quad$ Bekerja & 4 & 50 \\
Tidak bekerja & $\mathbf{8}$ & $\mathbf{1 0 0}$ \\
Jumlah & & \\
\hline
\end{tabular}


Tabel 2: Self-care Sebelum dan Setelah Intervensi

\begin{tabular}{|c|c|c|}
\hline \multirow[t]{2}{*}{ Variabel } & \multicolumn{2}{|c|}{ Frekuensi } \\
\hline & Pre & Post \\
\hline Self-Care Tinggi & $1(12,5 \%)$ & $5(62,5 \%)$ \\
\hline Self-Care Rendah & $7(87,5 \%)$ & $3(37,5 \%)$ \\
\hline Jumlah & $8 \quad(100 \%)$ & $8(100 \%)$ \\
\hline
\end{tabular}

\section{HASIL}

Tabel 1 dapat diinterpretasikan bahwa dari 8 orang pasien, rata rata berumur 52,7 tahun, sebagian besar responden berjenis kelamin laki-laki $(62,5 \%)$, pendidikan terakhir yang terbanyak SD $(62,5 \%)$, sebagian besar dengan status pernikahan yang terbanyak sudah menikah $(87,55)$ dan separuhnya tidak bekerja $(50,5 \%)$.

Berdasarkan table 2 dapat diinterpretasikan bahwa sebelum dilakukan intervensi digital storytelling (pre-test), hampir sebagian besar responden memiliki self-care rendah $(87,5 \%)$, dan selebihnya $(12,5 \%)$ memiliki self-care tinggi. Namun setelah dilakukan intervensi digital storytelling, lebih dari setengah responden memiliki self-care tinggi $(62,5 \%)$.

\section{PEMBAHASAN}

Berdasarkan nilai hasil klinis diatas, dapat ditarik kesimpulan bahwa secara klinis maupun statistik terdapat perbedaan self-care ostomate setelah diberikan intervensi digital storytelling. Perbedaan yang dimaksud adalah adanya peningkatan nilai self-care ostomate pasca pemberian intervensi digital storytelling.

Pada Penelitian lainnya pada penyakit yang berbeda terkait storytelling atau terapi bercerita atau mendengarkan cerita telah pernah dilakukan (Allison et al., 2016; Hargraves, Bonollo, \& Person, 2018; Miller, Weech-Maldonado, et al., 2016). Penderita Hipertensi dapat meningkatkan control diri melalui metode story telling adaptive Allison et al., (2016)

Houston, et al (2011) juga meneliti tentang metode story telling yang tepat untuk meningkatkan tekanan darah. Lee Hargraves et al(2018) menggunakan kisah pasien sebagai intervensi untuk mendukung manajemen hipertensi. Kemudian penelitian oleh Miller et al., (2016) mengevaluasi intervensi story telling dengan media DVD untuk meningkatkan komunikasi antar pasien-dokter tentang penggunaan obat NSAID. Penelitianpenelitian tersebut menunjukkan perubahan yang signifikan dari intervensi bercerita yang dilakukan sesuai dengan sasaran penderita yang akan diberikan edukasi.

\section{KESIMPULAN DAN SARAN}

Terjadi peningkatan self-care ostomate setelah pemberian edukasi story-telling hal ini salah satunya karena dipengaruhi oleh berbagai macam factor seperti agama, status pernikahan, usia, pendidikan dan pekerjaan. Perlunya perawat menjadikan sebagai program rutin yang dilakukan khususnya pada pendarita baru untuk menuntun dan mendorong peningkatan self-care pasien

\section{UCAPAN TERIMA KASIH}

Ucapan terima kasih kepada seluruh tim pengabdian, kepala ruangan beserta para perawat Lontara atas 1 RS.Dr.Wahidin dan seluruh penderita yang terlibat dalam kegiatan ini. 


\section{DAFTAR PUSTAKA}

Allison, J. J., Nguyen, H. L., Ha, D. A., Chiriboga, G., Ly, H. N., Tran, H. T., (2016). Culturally adaptive storytelling method to improve hypertension control in Vietnam“ We talk about our hypertension ": study protocol for a feasibility cluster-randomized controlled trial, 1-9.

Black, joyce M., \& Hawks, jane hokanson. (2009). Medical Surgical Nursing. (N. suslia, aklia S.Kep. \& F. S. Ganiajri, Eds.) (8th ed.). Jakarta.

Burch, J. (2011). 16 british journal of community nursing stoma management: enhancing patient knowledge.

Hargraves, J. L., Bonollo, D., \& Person, S. D. (2018). A randomized controlled trial of community health workers using patient stories to support hypertension management: Study protocol. Contemporary Clinical Trials.

Houston, Thomas K.; Allson, Jeroan J.; Sussman, M.; Horn, W.; Holt, C.L.; Trobaugh, J.; Salas, M.; Pisu, M.; Cuffee, Y.L.; Larkin, M.; Person, S.D; Barton, B.; Kiefe, C.I.; Hullett, S. (2011). Original Research Culturally Appropriate Storytelling to Improve Blood Pressure. Annals of Internal Medicine, 154(2), 78-89.
Kirkland-Kyhn, H., Martin, S., Zaratkiewicz, S., Whitmore, M., \& Young, H. M. (2018). Ostomy Care at Home. American Journal of Nursing, 118(4), 63-68.

Miller, M. J., Weech-maldonado, R., Outman, R. C., Ray, M. N., Gary, L. C., Chen, L., ... Saag, K. G. (2016). Patient Education and Counseling Evaluating the effectiveness of a patient storytelling DVD intervention to encourage physician-patient communication about nonsteroidal anti-in fl ammatory drug ( NSAID ) use. Patient Education and Counseling, 8-15.

Wieland, M. L., Njeru, J. W., Hanza, M. M., Boehm, D. H., Singh, D., Yawn, B. P., ... Sia, I. G. (2017). Pilot Feasibility Study of a Digital Storytelling Intervention for Immigrant and Refugee Adults With Diabetes. Diabetes Educator, 43(4), 349-359.

Snyder, M., \& Lindquist, R. (2010). Complementary \& Alternative Therapies in Nursing.

Summers, M. C. (2018). The Effect of Ostomate-to-Ostomate Support on Psychosocial Adaptation to Stoma.

Yayasan Kanker Indonesia (YKI). (2014). Jakarta. 